\title{
Incongruity-resolution in English Humor
}

\author{
Yufeng Bai \\ Faculty of Foreign Languages, Ningbo University, Ningbo, China \\ Email: baiyufeng@nbu.edu.cn
}

\begin{abstract}
Humor is a common phenomenon in language. One importance prerequisite of its humor effect lies in its incongruity, in the framework of relevance theory that is, the deviation from relevance expectations. According to the features of incongruity-resolution, the article makes the following classification of the humor: garden-path, cognitive contrast and inferring the implication.
\end{abstract}

Index Terms - relevance theory, humor effect, incongruity-resolution

\section{INTRODUCTION}

Humor is a common phenomenon in language. It exists in every corner of our life. And it can serve various social functions: break the ice, lubricate a serious condition, satire, ridicule and criticize, to just name a few. Its universality and versatile social functions determine its research value.

In recent years, many scholars are turning their attention to the phenomenon of humor (see Yus, 2003; Wang Wenbin \&Linbo, 2003; Fang Biyue \& Zhang Zhijiang, 2007; Wang Yong, 2001; Liu Naishi, 2005; Liu Ping, 2006). These studies research the cognitive mechanism involved in humor comprehension in the perspective of relevance theory and conceptual blending or the combination of the two theories, but in view of the versatility of humor in life, this article holds all the above studies lack the research into the classification of the humor from the cognitive aspect. And this leads to the task of this article: make a classification of humor according to the features of incongruity-resolution in the framework of relevance theory.

\section{INCONGRUITY AND INCONGRUITY-RESOLUTION}

Incongruity theory is the reigning theory of humor, for this theory illustrates the laughter-eliciting mechanism of humor. The incongruity theory of humor holds that the incongruity or inconsistent part is a prerequisite for a joke to produce humorous effect. But the incongruity alone cannot produce humor effect; it mainly depends on the resolution of the incongruity, that is, the process making the incongruity to be shown logical, or at least less incongruous than was first thought (Ritchie, 1999).

Immanuel Kant (1790) is credited to the advancement of the concept of incongruity. He suggests that humor arises when a strained expectation reduces suddenly to nothing (Kant, 1790, P.538). And later Beatthie's definition of incongruity gets widely accepted: "Laughter arises from the view of two or more inconsistent, unsuitable, or incongruous parts or circumstances, considered as united in one complex object or assemblage, or as acquiring a sort of mutual relation from the peculiar manner in which the mind takes notice of them"(Richie,2004, P.46). And the incongruity mainly lies between a joke's punch line and setup. For instance:

(1) A: Waiter! There is a fly in my soup!

B: Don't worry, sir. There is no extra charge.

There exists an incongruity between the customer's words and waiter's answer. But incongruity alone cannot create humor. The humorous effect mainly comes from the resolution of the incongruity-the realization of communicators' intentions with the help of the context. In the above example, customer's words literally are a statement, but in the context of a restaurant, it is a complaint. His intention is to get the waiter's apology. But the waiter intentionally pays no attention to the intention or expectation of the customer, just responds to the customer's literal meaning, thus producing the humorous effect.

\section{RELEVANCE THEORY}

Relevance Theory is one basic pragmatic theory, which is based on a definition of relevance and two principles of relevance. By relevance, According to RT, it refers to the connection between the new input and the background information. Relevance theory holds that relevance is a potential property of utterances and other observable phenomena such as thoughts, memories, sounds and so on. Relevance is determined by two factors: cognitive effect and cognitive effort. Cognitive effect refers to the relationship between the information of the discourse and the context. Cognitive effect is proportional to the relevance of the discourse. In communication, three relationships between new input and context can produce cognitive effect: 1) new input combines with the contextual assumptions, producing the new contextual implication; 2) new input strengthens the contextual assumptions; 3) new input contradicts the contextual assumptions, and abandons the contextual assumptions (Sperber and Wilson, 2001, P.109). Cognitive effort 
is the effort used in processing the discourse; it is inversely proportional to the relevance of the discourse.

The aim of human cognition tends to get the maximization of relevance. That is to say, to achieve the greatest possible effects for the smallest possible effort. This is the cognitive principle of relevance. But in verbal communication, each utterance will create the expectations of optimal relevance, and this is the communication principle of relevance. The two compose the relevance principle in the Relevance Theory.

Cognitive context is an important contempt in relevance theory. Cognitive context refers to the psychological construct, and it is part of the assumptions about the world; and it is dynamic, always changing in the process of discourse interpretation. According to relevance theory, the process of inferring is to some extent for the listener to search for cognitive context. In communication, the speaker shows the listener his informative and communicative intention by means of ostensive behaviors, thus providing necessary grounds of judgment for inference. Meanwhile the listener presupposes the discourse is relevant and worth processing then forms proper contextual assumptions according to the speaker's ostensive behaviors. The final aim is to reach optimal relevance. So to infer is to search relevance. In fact, the listener will make more than one assumption toward one word; only those compatible with the context will be accepted.

\section{HUMOR FROM THE PERSPECTIVE OF RELEVANCE THEORY}

Though not meant for humor, relevance theory provides a good account of the incongruity and incongruity-resolution in the humor. According to relevance theory, relevance is the property of all kinds of communication. And the process of discourse interpretation is the process of searching for relevance; we can say the incongruity in the humor refers to the deviation from the relevance expectation. As for incongruity-resolution, according to Sperber and Wilson (1986), when a speaker violates a convention, the listeners know exactly what to do: they search for a context that will render the violation intelligible. When the listener spends extra efforts to make the punch line logical or intelligible, his efforts will be rewarded by humorous effect when he finally makes it.

Consequently, I suggest that we can identify several types of humor by paying attention to the features of incongruity-resolution.

\section{A. Garden-path}

This type of humor contains a punning ambiguous part. According to cognitive principle of the Relevance Theory, the first meaning of the pun is more accessible than the other, so is activated first, the other meaning on standby. The punch line deviates from the relevance expectation created by the setup. The listener has to search for a proper assumption to solve the incongruity, which leads to the activation of the other meaning of the pun. Thus, the punch line becomes compatible with the setup. Consider the following examples:

(2) A six-year-old boy returned home after his first school day and said to his mother excitedly: "Mum, our beautiful teacher kissed me when I said good-bye to her this afternoon." "How nice! Did you kiss her back?" asked his mother. "Oh, no. I kissed her face."

(3) A well-to-do couple walk into a bar and sit down next to a drunk. Suddenly, the drunk lets out a tremendously loud fart.

"Excuse me! How dare you fart before my wife!" the man yells.

"Oh, sorry," the drunk slurs. "I did not know it was her turn."

(4) "I had a round of golf with my wife this morning," a man told his friend.

"Which won?" asked the friend.

The man didn't answer.

"Which won?" asked the friend a second time.

"Which one?" thundered the man, "how many wives do you think I have?!"

The joke (2) contains a punning part, which has two meanings. Kiss back not only means kiss in return, but also kiss someone's back. According to the cognitive principle of relevance, the meaning kiss in return is more accessible than the other, especially with the aid of previous words such as say goodbye, school. Later, the punch line violates the relevance expectation created by the setup, the listener has to search for other presumptions, and thus activating the other meaning of kiss back, in this way, the punch line gets compatible with the setup.

The same occurs with before my wife in Joke (3). The interpretation of in the presence of my wife is more accessible than in advance of my wife according to the cognitive principle of relevance. But the first accessible interpretation is later invalidated by the punch line. The effort to find a relevant explanation for the punch line activates the other meaning - in advance of my wife.

Joke (4) plays with a phonetic pun - which won and which one. When one said he played gold with his wife, the listener can only respond by asking which won, rather than which one, for in the world, most countries implement monogamy. Though a few countries in Middle East and Africa practice polygamy, it is just an exception, needs more efforts or imagination to get it. So the item which one is not as accessible as which won. But later, in order to resolve the incongruity, which one is activated.

\section{B. Cognitive Contrast}


The role of setup is to create strong relevance expectation. The appearance of the punch line deviates from these expectations, thus forming strong cognitive contrast and producing humorous effect as well. Take, for instance, the jokes below:

(5) A man and a friend are playing golf one day at their local golf course. One of the guys is about to chip onto the green when he sees a long funeral procession on the road next to the course. He stops in mid-swing, takes off his golf cap, closes his eyes, and bows down in prayer.

His friend says: "Wow that is the most thoughtful and touching thing I have ever seen. You truly are a kind man."

The man then replies: "Yeah, well, we were married 35 years."

(6) One day a lawyer was riding in his limousine when he saw a guy eating grass. He told the driver to stop. He got out and asked him, "Why are you eating grass?"

The man replied, "I am so poor. I can't afford a thing to eat."

So the lawyer said, "Poor guy, come back to my house."

The guy then said, "But I have a wife and three kids." The lawyer told him to bring them along.

When they were all in the car, the poor man said, "Thanks for taking us back to your house. It is so kind of you."

The lawyer said, "You are going to love it there. The grass is a foot tall."

(7) A woman gets on a bus with her baby. The bus driver says: "That's the ugliest baby that I've ever seen. Ugh!" The woman goes to the rear of the bus and sits down, fuming. She says to a man next to her: "The driver just insulted me!" The man says: "You go right up there and tell him off -- go ahead, I'll hold your monkey for you."

In (5), while two friends are playing golf, one funeral procession comes by. One friend takes off his hat, bowing down and praying. The other friend (interpreter) naturally comes to the conclusion that he is such a nice guy. His presumption is the dead is a stranger. But the punch line not only deviates from but completely goes contrary to this presumption. By this time, we know the dead is not a stranger, but his wife for 35 years! Thus the punch line forms a strong cognitive contrast with the setup, which might well be found amusing.

In (6), by strengthening again and again, the setup produces a very strong expectation that the kind and rich lawyer will bring the hungry man and his family home to eat. But the punch line contrasts sharply with this relevance expectation. Instead of bringing them back to eat, the lawyer will use them as a lawn mower!

In (7), when the driver said to the woman that her child was ugly, the man next to the woman seems very indignant by saying go ahead and tell him to shut up. We can form a strong expectation that this man is a gentleman and he would not be as impolite as the driver. But the last word of the man completely deviates from our expectation. He said the child is a monkey, and even more impolite than the driver.

\section{Inferring the Implication}

At first, the punch line seems irrelevant to the setup. To resolve the incongruity, the interpreter has to infer the implication of the punch line with the help of the cognitive context. By inferring the implication, the punch line gets compatible with the setup. Consider the following:

(8) The man bought a cigar in a department store and lit it while still in the store. A clerk told him to put it out because smoking was not allowed in the store.

"What do you mean?" he said. "You sell cigars but don't allow smoking."

"We also sell bath towels", said the girl sweetly. (Wang wenbin and Linbo.2003, P.37)

(9) Tom: What is your step-mother like?

Bob: She is a woman and she married my father.

(10) A woman goes to England to attend a 2-week company training session. Her husband drives her to the airport and wishes her to have a good trip.

The wife answered: Thank you honey, what would you like me to bring for you?

The husband laughed and said: An English girl!!!

The woman kept quiet and left. Two weeks later he picked her up in the airport and asked: So honey how was the trip?

The wife: Very good, thank you.

The husband: And, what happened to my present?

The wife: Which present?

The husband: What I asked for: the English girl?

The wife: Oh, that! Well, I did what I could; now we have to wait a few months to see if it's a girl!!!

In Joke (8), at first, the interpreter will feel the punch line-We also sell bath towels irrelevant to the customer's complaint-You sell cigars but don't allow smoking, seemly violating the relevant expectations. But when we have a further thought, it is not difficult to infer the implication of the punch line. The girl implies: if keeping in line with the man's logic (selling cigarette entitles the customers to smoking cigarette at store), the store will allow customers to have a bath at store if it sells bath towels. Apparently it is a ridiculous outcome inferred from a wrong logic. After inferring the implication of the punch line, we can resolve the incongruity, and thus get some amusement as well.

In Joke (9), Tom asks Bob's opinion about his stepmother, this question sets up the following relevant expectation: the answer usually will be she is good or bad. But the punch line obviously violates this expectation. It seems irrelevant to the question, and full of nonsense words, for to be a stepmother, she must be a female and marry the boy's father. 
Understanding Bob's words are relevant to the question, hearer (interpreter) infers the implication of the words with the help of the cognitive context: Bob does not like his stepmother and would not like to talk about it openly.

Finally, Joke (10) offers a punch line which seems irrelevant to the husband's question. But if the interpreter is an adult with certain encyclopedic knowledge, he/she can easily infer the implication of the wife's words: in revenge for the husband's wish - bring an English girl for him, the wife had an affair with an English man and got pregnant. And the only trouble is that she would not know if it is a girl until months later.

\section{CONCLUDING REMARKS}

This article researches psychological mechanism in the humor interpretation from the perspective of relevance theory, and classify the humor according to the features of incongruity-resolution. I. Garden-path. This type of humor contains a punning ambiguous part. One meaning of the pun is more accessible than the other. The punch line deviates from the relevance expectation. In searching for a proper assumption to solve the incongruity, the other meaning of the pun is activated and thus the punch line becomes compatible with the setup. II. Cognitive Contrast. The punch line not only deviates from but also forms a strong cognitive contrast with the setup. III. Inferring the Implication. The interpreter has to infer the implication of the punch line to make the punch line compatible with the setup. In view of the versatility of the humor in real life, there might be other types of incongruity-resolution, which need us to make research later.

\section{REFERENCES}

[1] Yus, Francisco. (2003). Humor and the search for relevance. Journal of Pragmatics 35.

[2] Wang Wenbin \& Linbo. (2003). English Verbal Humor: A Cognitive Pragmatic Inquiry. Journal of Foreign languages. 4,32-38.

[3] Fang Biyue \& Zhang Zhijiang. (2007). The Relevance-Integration Model of Verbal Humor-Some Disagreements with Wang Wenbin and Lin Bo. Journal of TianJin Foreign Studies University. 2,25-31.

[4] Wang Yong. (2001). A Study of Humorous Utterances from the Perspective of Relevance Theory. Foreign Language Education. 1,23-27.

[5] Liu naishi. (2005). Humor Incongruity and Resolution from the Perspective of Relevance Theory. Journal of PLA University of Foreign Languages. 1, 16-23.

[6] Liu Ping. (2006). Appreciation of English Verbal Humor from a Cognitive Pragmatics' Perspective. Journal of GuangDong University of Foreign Studies. 2,31-35.

[7] Ritchie, Graeme. (1999). Developing the Incongruity-Resolution Theory. Informatics Research Report.

[8] Kant, I. (1790). The Critique of Judgment, Trans J. C. Meredith, (1952) Chicago: Wm Benton.

[9] Richie, Graeme. (2004). The linguistic Analysis of Jokes. London: Routledge.

[10] Sperber D \& Wilson D. (1986 \& 2001). Relevance: Communication and Cognitions. Beijing: Foreign Language Teaching and Research Press.

Yufeng Bai was born in Luoyang, China in 1973. She received her M.A. degree in English Linguistics and Literature from Henan Normal University, China in 2003.

She is currently a lecturer in Ningbo University, Ningbo, China, teaching English. Her research interests include Pragmatics, English Literature. 